\title{
There is no Dose-response Relationship between Allogeneic Blood Transfusion and Healthcare- associated Infection: A Retrospective Cohort Study
}

Yu Lv

Sichuan Academy of Medical Sciences and Sichuan People's Hospital https://orcid.org/0000-00028069-4801

Qian Xiang

Sichuan Academy of Medical Sciences and Sichuan People's Hospital

Jia Lin

Sichuan Academy of Medical Sciences and Sichuan People's Hospital

Ying Zong Jin

Hospital(T.C.M) Affiliated to Southwest Medical University

\section{Ying Fang}

Jianyang People`s hospital

\section{Hong M Cai}

Sichuan Academy of Medical Sciences and Sichuan People's Hospital

\section{Qiong D Wei}

Sichuan Academy of Medical Sciences and Sichuan People's Hospital

Hui Wang

Sichuan Academy of Medical Sciences and Sichuan People's Hospital

\section{Chen Wang}

Sichuan Academy of Medical Sciences and Sichuan People's Hospital Jing Chen

Sichuan Academy of Medical Sciences and Sichuan People's Hospital Jian Ye

Sichuan Academy of Medical Sciences and Sichuan People's Hospital

\section{Caixia Xie}

Sichuan Academy of Medical Sciences and Sichuan People's Hospital

Ting L Li

Sichuan Academy of Medical Sciences and Sichuan People's Hospital

Yu J Wu ( $＼mathrm{~ l v y 123567 @ s i n a . c o m ~) ~}$

\section{Research}


Keywords: Healthcare-associated infection, Allogeneic blood transfusion, Restricted cubic spline regression

Posted Date: January 18th, 2021

DOI: https://doi.org/10.21203/rs.2.17342/v3

License: (1) This work is licensed under a Creative Commons Attribution 4.0 International License. Read Full License

Version of Record: A version of this preprint was published at Antimicrobial Resistance and Infection Control on March 29th, 2021. See the published version at https://doi.org/10.1186/s13756-021-00928-5. 


\section{Abstract}

Background The association between allogeneic blood transfusion (ABT) and healthcare-associated infection (HAl) is considered dose-dependent. However, this association may be confounded by transfusion duration, as prolonged hospitalization stay increases the risk of HAl. Also, it is not clear whether specific blood products have different dose-response risks.

Methods In this retrospective cohort study, a logistic regression was used to identify confounding factors, and the association between specific blood products and HAl were analyzed. Then Cox regression and restricted cubic spline regression was used to visualize the hazard of HAI per transfusion product.

Results Of 215338 inpatients observed, $4.16 \%$ were transfused with a single component blood product. With regard to these transfused patients, 480 patients (5.36 \%) developed a HAI during their hospitalization stay. Logistic regression showed that red blood cells (RBCs) transfusion, platelets transfusion and fresh-frozen plasmas (FFPs) transfusion were risk factors for HAI [odds ratio (OR) 1.893, 95\% confidence interval (CI) 1.656-2.163; OR 8.903, 95\% Cl 6.646-11.926 and OR 1.494, 95\% Cl 1.1461.949 , respectively]. However, restricted cubic spline regression analysis showed that there was no statistically dose-response relationship between different transfusion products and the onset of HAI.

Conclusions RBCs transfusion, platelets transfusion and FFPs transfusion were associated with HAl, but there was no dose-response relationship between them.

\section{Introduction}

The association between allogeneic blood transfusion (ABT) and healthcare-associated infection (HAI) in hospitalized patients has been described in many studies [1-4]. Whether it is a specific type of infection or a pooled multiple different types of HAl, ABT is considered to increase the risk of HAI. This increased risk of infection is not thought to be due to the direct spread of infectious agents through blood transfusion, but blood transfusions make the body more susceptible to new infections. Allogeneic blood is immunologically active, and the immunosuppressive effects of allogeneic blood known as transfusionrelated immunomodulation (TRIM) is considered to be the leading cause of HAI [5]. The underlying mechanism of TRIM is not well understood and is thought to be related to the presence of white blood cells, mediators and bioactive agents [6].

Given the more opportunities the patient will be exposed to immunosuppression when the dose of blood transfusion administered greater, it is a challenge to determine whether increased risk of infection due to the number of transfused units. Previous studies have generally suggested that high doses of blood transfusion increase the risk of infection [7, 8]. However, this association may be confounded by transfusion duration, as prolonged length of hospitalization stay increases the risk of HAl. This is called time bias, which is a confounding factor in HAl-related epidemiological studies that needs to be considered for balance [9]. There are many ways to balance time bias, as mentioned in previous studies, such as matching, propensity scores, and COX regression $[10,11]$. 
Restricted cubic spline (RCS) regression is a powerful tool to characterize a dose-response association between a continuous exposure and an outcome, and to visually check the assumption of linearity of the association. This method has been used in many areas of medical research [12,13], but it is rarely used in the study of dose-response relationship between HAl and risk factors.

The purpose of this retrospective cohort study was to investigate the dose-response relationship between $A B T$ and HAl. Cox regression was used to adjust for the effect of time bias. Restricted cubic spline regression was used to visualize the hazard of HAl per transfusion product.

\section{Materials And Methods}

\section{Design and subjects}

A retrospective cohort study was performed in one of the largest tertiary A-level hospitals in Sichuan Province, China, in which all admissions between the period of 1 January 2017 and 31 December 2018 were included, with the exception of inpatients who were hospitalized within 2 calendar days.

\section{Cohorts}

This study included 4 cohorts, including cohort-RBCs, cohort-FFPs, cohort-cryo and cohort-platelets. Cohort-RBCs: Inpatients were transfused with RBCs during the study but did not transfuse any other blood product.

Cohort-FFPs: Inpatients were transfused with FFPs during the study but did not transfuse any other blood product.

Cohort-cryo: Inpatients were transfused with cryoprecitation during the study but did not transfuse any other blood product.

Cohort-platelets: Inpatients were transfused with platelets during the study but did not transfuse any other blood product.

\section{Outcomes}

The presence of healthcare-associated infection was the primary outcome of this study.

The diagnostic criteria were the "HAls Diagnostic Criteria" issued by the Ministry of Health of the People's Republic of China in 2001 [14]. HAls were defined as infections acquired by inpatients in hospitals, which included infections that occurred during hospitalization and those acquired in hospitals but occurred after discharge. The criteria excluded infections that occurred prior to or at the time of admission.

All reported cases of HAls were examined by three infectious disease specialists to ensure accurate identification of the infected cases. 


\section{Risk factors for HAl}

Potential confounders were selected based on previous literature [15-18], and included age, gender, principal diagnosis, diabetes, hypertension (systolic blood pressure $\geq 140 \mathrm{mmHg}$ and/or diastolic blood pressure $\geq 90 \mathrm{mmHg}$ [19]), chronic obstructive pulmonary disease, hemodialysis, venous catheterization, mechanical ventilation, urinary catheterization, tracheotomy, surgery, ICU admission now or in the past and community infections.

\section{Data collection}

Data was obtained from 3 information systems, including inpatient records system, blood transfusion records system and HAI management information system.

Only ABT given before the onset of HAl were evaluated. Per blood product, a qualitative variable (transfusion yes or no), and 2 quantitative variables (amount of product in units and frequency of transfusion) were generated.

\section{Statistical analysis}

We analyzed the dose-response relationship between blood transfusion components and HAls using a two-step approach described below. First, we evaluated risk factors associated with HAls. A logistic regression model with HAls as the dependent variable was used, and the association between HAls and RBCs, FFPs, cryoprecitation or platelets were analyzed. Second, Cox regression was performed with the same independent variables as in step 1, and restricted cubic spline regression was used to visualize the hazard of HAl per transfusion product.

Data were summarized using the mean and standard deviation (SD) for normally distributed variables and the median and inter-quartile range (IQR) for non-normally distributed variables. Categorical variables were expressed in absolute numbers and percentages. Statistical analysis of the data was performed using STATA 12.0. Binary outcomes were tested using the $\chi 2$ test, and continuous data were compared using Mann-Whitney test or the T-test. $P$ values below 0.05 were considered significant.

\section{Results}

\section{Patient inclusion}

A total of 257984 inpatients were admitted to the hospital, including 3079 patients with HAI. The first step in this study, 38472 patients who were hospitalized within 2 calendar days and 4174 patients who underwent multiple component transfusions were excluded. Finally 3079 inpatients with HAl and 212259 inpatients without HAI were included. In the second step, 206385 patients who did not undergo transfusions were excluded. Finally 480 inpatients with HAI and 8473 inpatients without HAI were included. See Figure 1 for details. 


\section{Characteristics of patients}

Of 215338 inpatients, $4.16 \%$ were transfused with a single component blood product. With regard to these transfused patients, 480 patients $(5.36 \%$ ) developed a HAI during their hospitalization stay. Among them, the incidence of HAl caused by platelets transfusion was the highest (8.53\%), followed by FFPs transfusion (5.93\%), cryoprecitation transfusion (5.08\%), RBCs transfusion (4.91\%). Characteristics summarized for the patients with HAl and without HAl were listed in Table 1.

The median RBCs amount and transfusion frequency of patients who developed a HAI were longer compared to patients who did not develop a HAl [2 (IQR 2-3) vs. 2 (IQR 2-4) units and 1 (IQR 1-2) vs. 1 (IQR 1-3) times, respectively]. The median platelets amount of patients who developed a HAI was longer compared to patients who did not develop a HAI [1 (IQR 1-2) vs. 1 (IQR 1-3) units, respectively]. Table 2 shows these details.

\section{Logistic regression}

Logistic regression identified RBCs transfusion, FFPs transfusion, platelets transfusion, age, gender, principal diagnosis, diabetes, hypertension, chronic obstructive pulmonary disease, hemodialysis, venous catheterization, mechanical ventilation, urinary catheterization, tracheotomy, surgery, ICU admission now or in the past and community infections as independent predictors for HAl. The details are shown in Table 3.

\section{Restricted cubic spline regression}

Restricted cubic spline regression analysis showed that there was no statistically dose-response relationship between different transfusion products and the onset of HAl, as Fig. 2- Fig. 4 shows. Because cryoprecitation has not been found to be an independent risk factor for HAl in logistic regression, it was not included in this section.

\section{Discussion}

This study found that RBCs transfusion, FFPs transfusion and platelets transfusion were independent risk factors for $\mathrm{HAl}$, while cryoprecitation was not. A restrictive transfusion strategy may be an important first step to infection prevention. A previous meta-analysis concluded that a restrictive transfusion strategy was associated with a reduced risk of HAI when compared with a liberal transfusion strategy [20]. As such, clinicians need to actively seek alternatives to transfusion before evaluating the risks and benefits of transfusion in individual patients [21]. Our study also found that the differences in HAl risk caused by different blood products are significant. Obvious differences in HAI risk may have an impact on the definition of HAI susceptible population and the formulation of prevention and control strategies. However, even with restrictive transfusion, adherence to adoption of certain blood products for ondemand treatment is an important second step in preventing HAI. 
In our study, platelets transfusion had the highest OR value, which was much greater than any other risk factor. Like previous studies [1,22, 23], the increased HAl risk due to platelets transfusion was highlighted, and platelets transfusion was considered to be the most important blood products associated with HAl in ours study. In line with a prospective multicenter cohort study from Netherlands [24], it was unlikely that RBCs contributed to the risk of infections when administered together with platelets. Although the effectiveness of platelet transfusions to prevent bleeding had been affirmed at a platelet count of $10 \times 10^{9} / \mathrm{L}$ in acute leukemia patients [25], it lacked data support in other patients. There is a clear indication for platelets transfusion only in hematology patients [26, 27]. Given the association between platelet transfusion and increased HAI risk, we believe that a risk benefit analysis should be conducted in relation to continued platelet transfusion.

We found that there was no dose-response relationship between ABT and HAI. Regardless of the type of transfusion product, the hazard ratio of HAI was not linearly related to their transfusion units or frequency. This is in contrast to other studies [28-30], which demonstrated an association between transfusion and complications was dose-dependent. However, these dose-response relationships are not entirely credible, because the division of dose groups in these studies is completely different, without any reference. We believe that potential classification errors are likely to lead to biased results. Similarly, this difference might be explained by the use of different statistical analysis methods. Our results were based on both Cox regression and restricted cubic spline regression, whereas in previous studies, the length of time from the first blood transfusion to infection was ignored, resulting in a large time bias. In addition, different preparation methods and storage schemes might also be the cause of this difference. Consistent with our findings, a study from the United States found that there did not seem to be a doseresponse relationship between the number of blood units transfused and any of the postoperative infections [31].

Optimal use of blood transfusions should involve administering enough to maximize clinical outcomes while avoiding unnecessary exposure to the HAl risk [32]. To achieve this almost impossible ideal state, more evidence-based guidelines are needed to provide clinicians with feasible methods. Our findings did not appear to be clinically relevant, but could eliminate concerns about doses during blood transfusions. If blood transfusion was unavoidable according to the patient's condition, methods to administer enough doses as well as to increase the effectiveness of each unit transfused would greatly benefit patients, by avoiding and preventing the occurrence of HAI. The practical significance of our findings might be of reference value in HAl monitoring and infection-related risk assessment. ABT in our study was an associated and apparently significant risk factor for the development of $\mathrm{HAl}$, but it was not defined as a risk factor in China's nosocomial infection surveillance guideline [33], leading to the neglect of $A B T$ in many previous studies [34-36]. Given that $A B T$ is such a significant and frequently overlooked risk factor for $\mathrm{HAl}$, it is necessary to include $A B T$ as invasive procedures and antimicrobial resistance into the daily targeted surveillance of HAI. We recommend that future studies of blood transfusion management should include HAI as a patient outcome so that transfusion-related immunomodulation can be more widely estimated and evaluated. 
Previous studies have indicated that the storage time of blood products may be central to their immune modulatory effect. Khan et al. found that soluble CD40 ligand accumulated in stored blood components, primes neutrophils through CD40, and was a potential cofactor in the development of transfusion-related acute lung injury [37]. Kristiansson et al. found that stored RBCs had high levels of cytokines but that the specific cytokine levels varied as a function of the age of the blood. Interleukin-1 levels, for instance, increased with time, whereas interleukin- 6 levels remained elevated throughout the duration of RBCs storage [38]. However, the storage time of blood products was not analyzed in our study because the transfusion of older blood products compared with fresher blood products was not associated to worse clinical complication in recent large trial studies $[39,40]$.

We acknowledge several limitations in our study. Most importantly, transfusion-related immunomodulation varied across specific types of infections. Our study has pooled multiple different types of HAI. Thus, the potential dose-response relationship between a specific type of infection and ABT may be ignored. Further studies are needed to distinguish the types of infection, to further explore the dose-response relationship between specific types of infection and ABT. Furthermore our study was retrospective and only involved the analysis of a hospital. Larger multi-center randomized studies should be conducted to validate our findings.

\section{Conclusions}

Our study found that RBCs transfusion, platelets transfusion and FFPs transfusion were associated with HAl, but there was no dose-response relationship between them. If blood transfusion was unavoidable, we recommend administering enough doses to maximize clinical benefit.

\section{Declarations}

\section{Contributions}

Yu J Wu and Ying Z Jin conceived of this project. Yu Lv and Jia Lin developed the study design. Qian Xiang, Qiong D Wei, Hui Wang, Chen Wang, Hong M Cai, Jian Ye and Jing Chen assisted with information collection. Yu Lv and Ying Fang co-wrote the manuscript text. All authors had final approval of the submitted manuscript.

\section{Acknowledgements}

We are grateful to the healthcare-associated infections quality control center in Sichuan province for advice on study design.

\section{Consent for publication}

Not applicable

\section{Corresponding author}


Corresponding author: Yu J Wu, Email: Ivy123567@sina.com.

Post-publication corresponding author: Chen Wang,Email: 534127551@qq.com.

Alternate corresponding authors $\square$ Yu Lv, Email:29381636@qq.com.

\section{Data availability statement}

All data generated and analyzed during this study are included in this article.

\section{Ethics approval and consent to participate}

Not applicable

\section{Conflict of Interest}

No conflict of interest exits in the submission of this manuscript.

\section{Funding}

This project has received funding from the Health and Family Planning Commission of Sichuan Province (18PJ571).

\section{References}

1. Shander A, Lobel GP, Javidroozi M. Transfusion practices and infectious risks. Expert Review of Hematology, 2016:17474086.2016.1164593.

2. Hill GE, Frawley WH, Griffith KE, et al. Allogeneic Blood Transfusion Increases the Risk of Postoperative Bacterial Infection: A Meta-analysis. The Journal of Trauma: Injury, Infection, and Critical Care, 2003, 54(5):908-914.

3. Teng Z, Zhu Y, Liu Y, et al. Restrictive blood transfusion strategies and associated infection in orthopedic patients: a meta-analysis of 8 randomized controlled trials. Scientific Reports, 2015, 5:13421.

4. Friedman R. Allogeneic blood transfusions and postoperative infections after total hip or knee arthroplasty. Journal of Bone \& Joint Surgery-American Volume, 2014, 96(4):272-278.

5. Refaai MA, Blumberg N. Transfusion immunomodulation from a clinical perspective: an update. Expert Review of Hematology, 2013, 6(6):653-663.

6. Hart S, Cserti-Gazdewich CM, Mccluskey SA. Red cell transfusion and the immune system. Anaesthesia, 2015, 70:38-e16.

7. Norol F, Bierling P, Roudot-Thoraval F, et al. Platelet transfusion: A dose-response study. Blood, 1998, 92(4):1448-1453. 
8. Michalia M, Kompoti M, Panagiotakopoulou A, et al. Impact of red blood cells transfusion on ICUacquired bloodstream infections: A case-control study. Journal of Critical Care, 2012, 27(6):655-661.

9. Schulgen G, Kropec A, Kappstein I, et al. Estimation of extra hospital stay attributable to nosocomial infections: heterogeneity and timing of events. Journal of Clinical Epidemiology, 2000, 53(4):409417.

10. Yu L, Min H C, Jian C, et al. A multi-center nested case-control study on hospitalization costs and length of stay due to healthcare-associated infection. Antimicrobial Resistance \& Infection Control, 2018, 7(1):99.

11. Lv Y, Chen L, Yu J W, et al. Hospitalization costs due to healthcare-associated infections: An analysis of propensity score matching. Journal of infection and public health, 2019, 12(4):568-575.

12. Desquilbet $L$, Mariotti F. Dose-response analyses using restricted cubic spline functions in public health research. Statistics in Medicine, 2010, 29(9):1037-1057.

13. Churpek MM, Yuen TC, Winslow C, et al. Multicenter Comparison of Machine Learning Methods and Conventional Regression for Predicting Clinical Deterioration on the Wards. Critical Care Medicine, 2016, 44(2):368-374.

14. National Health and Family Planning Commission of the People's Republic of China. Notice on Issuing Diagnostic Criteria for Nosocomial Infection (Trial). http://www.nhc.gov.cn/wjw/gfxwj/201304/37cad8d95582456d8907ad04a5f3bd4c.shtml. [accessed 25 July 2019].

15. Marsteller J A. Multistate Point-Prevalence Survey of Healthcare-Associated Infections. N Engl J Med, 2014, 370(13):1198-1208.

16. Chen W S, Ni B Q, Li S Q, et al. Novel risk factors for the healthcare associated infections (HAls) in patients with Stanford type A aortic dissection (TAAD). Journal of Thoracic Disease, 2018, 10(4):2135-2141.

17. Amira M. Sultan, Wael A. Seliem. Identifying risk factors for Healthcare-associated infections caused by Carbapenem-Resistant Acinetobacter baumannii in a neonatal intensive care unit. Sultan Qaboos Univ Med J. 2018 Feb; 18(1): e75-e80.

18. Ali S, Birhane M, Bekele $S$, et al. Healthcare associated infection and its risk factors among patients admitted to a tertiary hospital in Ethiopia: Iongitudinal study. Antimicrobial Resistance \& Infection Control, 2018, 7(1):2.

19. Liu L S. 2010 Chinese guidelines for the management of hypertension. Chinese Journal of Hypertension, 2011, 39(2):579-615.

20. Jeffrey M Rohde, Derek E Dimcheff, Neil Blumberg, et al. Health care-associated infection after red blood cell transfusion: a systematic review and meta-analysis. Journal of the American Medical Association, 2014, 311(13):1317-1326.

21. National Health and Family Planning Commission of the People's Republic of China. Transfusion of whole blood and blood components. 
http://www.nhc.gov.cn/wjw/s9493/201810/9b96b65aaa824ffcac7d3e023da205ad.shtml. [accessed 1 October 2020].

22. Juffermans NP, Prins DJ, Vlaar AP, et al. Transfusion-related risk of secondary bacterial infections in sepsis patients: a retrospective cohort study. Shock, 2011, 35(4):355.

23. Micota B, Sadowska B, Różalska B. The role of blood platelets in infections. Postepy Hig Med Dosw, 2015, 69:624-632.

24. Engele LJ, Straat M, Van Rooijen IHM, et al. Transfusion of platelets, but not of red blood cells, is independently associated with nosocomial infections in the critically ill. Annals of Intensive Care, 2016, 6(1):67.

25. Susan N, Sherrill JS, Susano T, Paolo R, Katerina P, Ralph V, et al. Guidance on Platelet Transfusion for Patients with Hypoproliferative Thrombocytopenia. Transfusion Medicine Reviews, 2015, 29(1):313.

26. Estcourt LJ, Birchall J, Lowe D, GrantCasey J, Rowley M, Murphy MF. Platelet transfusions in haematology patients: are we using them appropriately? Vox Sang 2012;103:284-93.

27. Stanworth SJ, Estcourt LJ, Powter G, et al. A No-Prophylaxis Platelet-Transfusion Strategy for Hematologic Cancers. New England Journal of Medicine, 2013, 368(19):1771-1780.

28. Edna TH, Bjerkeset T. Association between blood transfusion and infection in injured patients. The Journal of Trauma: Injury, Infection, and Critical Care, 1992, 33(5), 659-661.

29. Kopriva BM, Helmer SD, Smith RS. Jack A. Barney Resident Paper Award: Blood transfusions increase complications in moderately injured patients. The American Journal of Surgery, 2010, 200(6):0-751.

30. Shorr AF, Duh MS, Kelly KM, et al. Red blood cell transfusion and ventilator-associated pneumonia: A potential link?. Critical Care Medicine, 2004, 32(3):666-674.

31. Stein JJ, Yvonne B, Kirkham BW, Thomas DC, Joseph H. Schwab. Allogeneic blood transfusions and postoperative infections after lumbar spine surgery. The Spine Journal, 2015, 15(5):901-909.

32. Carson JL, Grossman BJ, Kleinman S, Tinmouth AT, Marques MB, Fung MK, et al. Red Blood Cell Transfusion: A Clinical Practice Guideline From the AABB*. Annals of Internal Medicine, 2012, 157(1):49-58.

33. National Health and Family Planning Commission of the People's Republic of China. Standard for nosocomial infection surveillance. http://www.nhc.gov.cn/wjw/s9496/200904/40117.shtml. [accessed 1 October 2020].

34. Feng X F, Yang L C, Tan L Z, et al. Risk factor analysis of device-related infections: Value of resampling method on the real-world imbalanced dataset. BMC Medical Informatics and Decision Making, 2019, (2019) 19(1):185.

35. Li F, Song $M, X u L$, et al. Risk factors for catheter-associated urinary tract infection among hospitalized patients: a systematic review and meta-analysis of observational studies. Journal of Advanced Nursing, 2018. 
36. Zhu S, Kang Y, Wang W, et al. The clinical impacts and risk factors for non-central line-associated bloodstream infection in 5046 intensive care unit patients: an observational study based on electronic medical records. Critical Care, 2019, 23(1).

37. Khan SY, Kelher MR, Heal JM, et al. Soluble CD40 ligand accumulates in stored blood components, primes neutrophils through $\mathrm{CD} 40$, and is a potential cofactor in the development of transfusionrelated acute lung injury. Blood, 2006, 108(7):2455-62.

38. Kristiansson M, Soop M, Saraste L, et al. Cytokines in stored red blood cell concentrates: promoters of systemic inflammation and simulators of acute transfusion reactions?. Acta Anaesthesiologica Scandinavica, 2010, 40(4):496-501.

39. Lacroix J, Hébert PC, Fergusson DA, et al. Age of Transfused Blood in Critically III Adults. New England Journal of Medicine, 2015, 372(15):1410-8.

40. Steiner ME, Ness PM, Assmann SF, Triulzi DJ, Sloan SR, Delaney M, et al. Effects of Red-Cell Storage Duration on Patients Undergoing Cardiac Surgery. New England Journal of Medicine, 2015, 372(15):1419-1429.

\section{Tables}

Table 1 Baseline characteristics 


\begin{tabular}{|c|c|c|c|c|}
\hline Factors & $\begin{array}{c}\text { Overall } \\
(\mathrm{N}=215338)\end{array}$ & $\begin{array}{c}\text { Non-HAl } \\
(\mathrm{N}=212259)\end{array}$ & $\begin{array}{c}\text { HAl } \\
(\mathrm{N}=3079)\end{array}$ & $\mathbf{P}$ \\
\hline Age(years $\pm S D)$ & $51.59 \pm 21.74$ & $51.44 \pm 21.68$ & $61.71 \pm 23.5$ & $56<0.001$ \\
\hline \multicolumn{5}{|l|}{ ABT $[n(\%)]$} \\
\hline Non-ABT & $206385(95.84)$ & $203786(96.01)$ & ) 2599(84.41 & 1) $<0.001$ \\
\hline RBCs & 6868(3.19) & 6531(3.08) & $337(10.95)$ & \\
\hline Cryoprecitation & $59(0.03)$ & $56(0.03)$ & $3(0.10)$ & \\
\hline FFPs & $1264(0.59)$ & $1189(0.56)$ & $75(2.44)$ & \\
\hline Platelets & 762(0.35) & 697(0.33) & $65(2.11)$ & \\
\hline Gender [n (\%)] & $106812(49.60)$ & $104937(49.44)$ & ) $1875(60.90$ & 0) $<0.001$ \\
\hline Venous catheterization [n (\%)] & 13904(6.46) & $13189(6.21)$ & $715(23.22)$ & $<0.001$ \\
\hline Mechanical ventilation [n (\%)] & $4888(2.27)$ & $4290(2.02)$ & $598(19.42)$ & $<0.001$ \\
\hline Urinary catheterization [n (\%)] & 48195(22.38) & $46842(22.07)$ & $1353(43.94$ & 4) $<0.001$ \\
\hline Tracheotomy [n (\%)] & 1421(0.66) & 1194(0.56) & $227(7.37)$ & $<0.001$ \\
\hline Diabetes [n (\%)] & 29428(13.67) & $28730(13.54)$ & $698(22.67)$ & $<0.001$ \\
\hline Hypertension [n (\%)] & $52713(24.48)$ & $51392(24.21)$ & $1321(42.90$ & ) $<0.001$ \\
\hline Chronic obstructive pulmonary disease [n (\%)] & 7902(3.67) & 7545(3.55) & $357(11.59)$ & $<0.001$ \\
\hline ICU admission now or in the past $[\mathrm{n}(\%)]$ & $12997(6.04)$ & $12159(5.73)$ & $838(27.22)$ & $<0.001$ \\
\hline Hemodialysis [n (\%)] & $451(0.21)$ & $428(0.20)$ & 23(0.75) & $<0.001$ \\
\hline Surgery $[\mathrm{n}(\%)]$ & $110353(51.25)$ & $108675(51.20)$ & ) $1678(54.50$ & ) $<0.001$ \\
\hline Community infections [n (\%)] & 28396(13.19) & 27808(13.10) & $588(19.10)$ & $<0.001$ \\
\hline \multicolumn{5}{|l|}{ Principal diagnosis (ICU-10 code) [n (\%)] } \\
\hline Certain infectious diseases and parasites(A00-B99) & $6561(3.05)$ & 6404(3.02) & 157(5.10) & $<0.001$ \\
\hline Tumor (C00-D48) & $30975(14.38)$ & $30505(14.37)$ & $470(15.26)$ & \\
\hline $\begin{array}{l}\text { Blood and hematopoietic diseases and certain diseases involving immune } \\
\text { mechanisms (D50-D89) }\end{array}$ & 1735(0.81) & $1710(0.81)$ & 25(0.81) & \\
\hline Endocrine, nutritional, and metabolic diseases (E00-E90) & $5453(2.53)$ & $5355(2.52)$ & 98(3.18) & \\
\hline Mental and behavioral disorders (F00-F99) & $3717(1.73)$ & $3668(1.73)$ & $49(1.59)$ & \\
\hline Nervous system diseases (G00-G99) & $7870(3.65)$ & $7699(3.63)$ & $171(5.55)$ & \\
\hline Eye and appendage diseases ( $\mathrm{H} 00-\mathrm{H} 59)$ & $6051(2.81)$ & $6050(2.85)$ & $1(0.03)$ & \\
\hline Ear and mastoid diseases $(\mathrm{H} 60-\mathrm{H} 95)$ & 2092(0.97) & $2086(0.98)$ & $6(0.19)$ & \\
\hline Circulatory diseases (100-199) & $27682(12.86)$ & $27109(12.77)$ & $573(18.61)$ & \\
\hline Respiratory diseases (J00-J99) & $17848(8.29)$ & $17287(8.14)$ & $561(18.22)$ & \\
\hline Digestive diseases (K00-K93) & $26575(12.34)$ & $26383(12.43)$ & $192(6.24)$ & \\
\hline Skin and subcutaneous tissue diseases (L00-L99) & $3201(1.49)$ & $3176(1.50)$ & 25(0.81) & \\
\hline Musculoskeletal system and connective tissue diseases (M00-M99) & $11295(5.25)$ & $11124(5.24)$ & $171(5.55)$ & \\
\hline Genitourinary diseases (N00-N99) & $15174(7.05)$ & $15010(7.07)$ & 164(5.33) & \\
\hline Pregnancy, childbirth, and puerperium (000-099) & 11294(5.24) & 11256(5.30) & $38(1.23)$ & \\
\hline Diseases that originated in the perinatal period (P00-P96) & $1177(0.55)$ & $1137(0.54)$ & $40(1.30)$ & \\
\hline Congenital malformations, deformation, and chromosomal abnormalities (Q00- & $3595(1.67)$ & $3577(1.69)$ & $18(0.58)$ & \\
\hline Q99) & & & & \\
\hline $\begin{array}{l}\text { Abnormal symptoms, signs, clinical and laboratory results, and cannot be } \\
\text { classified in other categories (R00-R99) }\end{array}$ & $2663(1.24)$ & 2652(1.25) & $11(0.36)$ & \\
\hline Injury, poisoning and other external pathogenic factors (S00-T98) & 9192(4.27) & $9058(4.27)$ & 134(4.35) & \\
\hline External causes of illness and death (V01-V98) & $21188(9.84)$ & 21013(9.90) & $175(5.68)$ & \\
\hline
\end{tabular}

Table 2 Transfusion characteristics 


\begin{tabular}{|c|c|c|c|c|}
\hline Patients & Overall & Non-HAI & HAI & $\mathbf{P}$ \\
\hline \multicolumn{5}{|l|}{$\overline{\mathrm{RBCs}}$} \\
\hline No. & 6868 & 6531 & 337 & \\
\hline Amount of transfusion [median (IQR)] & $2(2-4)$ & $2(2-3)$ & $2(2-4)$ & $<0.001$ \\
\hline Frequency of transfusion [median (IQR)] & $1(1-2)$ & $1(1-2)$ & $1(1-3)$ & 0.013 \\
\hline \multicolumn{5}{|l|}{ Cryoprecitation } \\
\hline No. & 59 & 56 & 3 & \\
\hline Amount of transfusion [median (IQR)] & $1(1-1)$ & $1(1-1)$ & $1(1-1)$ & 0.521 \\
\hline Frequency of transfusion [median (IQR)] & $1(1-1)$ & $1(1-1)$ & $1(1-1)$ & 0.547 \\
\hline \multicolumn{5}{|l|}{ FFPs } \\
\hline No. & 1264 & 1189 & 75 & \\
\hline Amount of transfusion [median (IQR)] & $350(200-600$ & $350(200-600$ & $400(200-750)$ & 0) 0.315 \\
\hline Frequency of transfusion [median (IQR)] & $1(1-3)$ & $1(1-3)$ & $1(1-3)$ & 0.952 \\
\hline \multicolumn{5}{|l|}{ Platelets } \\
\hline No. & 762 & 697 & 65 & \\
\hline Amount of transfusion [median (IQR)] & $1(1-2)$ & $1(1-2)$ & $1(1-3)$ & 0.010 \\
\hline Frequency of transfusion [median (IQR)] & $1(1-2)$ & $1(1-2)$ & $1(1-2)$ & 0.060 \\
\hline \multicolumn{5}{|c|}{ Time between (first) transfusion and HAI (days) } \\
\hline RBCs & & & $9(6-15)$ & \\
\hline Cryoprecitation & & & $8(4-14)$ & \\
\hline FFPs & & & $10(6-16)$ & \\
\hline Platelets & & & $8(4-13)$ & \\
\hline
\end{tabular}

Table 3 Equation parameters of confounding factors affecting HAl 


\begin{tabular}{|c|c|c|c|c|}
\hline \multirow[t]{2}{*}{ Covariate } & OR & \multirow{2}{*}{\multicolumn{2}{|c|}{$\begin{array}{c}\text { 95\% C.I. for } \\
\text { OR } \\
\text { Lower Upper }\end{array}$}} & \multirow[t]{2}{*}{$\mathbf{P}$} \\
\hline & & & & \\
\hline Constant & / & / & / & $<0.001$ \\
\hline \multicolumn{5}{|l|}{ ABT } \\
\hline RBCs & 1.893 & 31.656 & 2.163 & $<0.001$ \\
\hline Cryoprecitation & 2.459 & 90.730 & 8.290 & 0.147 \\
\hline FFPs & 1.494 & 41.146 & 1.949 & 0.003 \\
\hline Platelets & 8.903 & 36.646 & 11.926 & $5<0.001$ \\
\hline Gender & 1.307 & 71.210 & 1.411 & $<0.001$ \\
\hline Venous catheterization & 1.897 & 71.693 & 2.126 & $<0.001$ \\
\hline Mechanical ventilation & 2.185 & 51.895 & 2.519 & $<0.001$ \\
\hline Urinary catheterization & 1.953 & 31.776 & 2.149 & $<0.001$ \\
\hline Tracheotomy & 5.473 & 34.607 & 6.501 & $<0.001$ \\
\hline Diabetes & 1.231 & 11.117 & 71.356 & $<0.001$ \\
\hline Hypertension & 1.475 & 51.350 & 1.612 & $<0.001$ \\
\hline Chronic obstructive pulmonary disease & 1.404 & 41.220 & 1.615 & $<0.001$ \\
\hline Age & 1.015 & 51.013 & 31.018 & $<0.001$ \\
\hline ICU admission now or in the past & 1.422 & 21.255 & 1.610 & $<0.001$ \\
\hline Hemodialysis & 2.110 & 01.337 & 3.329 & 0.001 \\
\hline Surgery & 1.107 & 71.022 & 1.198 & 0.012 \\
\hline Community infections & 1.218 & 81.084 & 41.368 & 0.001 \\
\hline \multicolumn{5}{|l|}{ Principal diagnosis (ICU-10 code) } \\
\hline Certain infectious diseases and parasites(A00-B99) & / & / & / & $<0.001$ \\
\hline Tumor (C00-D48) & 0.439 & 90.361 & 0.534 & $<0.001$ \\
\hline Blood and hematopoietic diseases and certain diseases involving immune mechanisms (D50-D89) & 0.523 & 30.334 & 40.820 & 0.005 \\
\hline Endocrine, nutritional, and metabolic diseases (E00-E90) & 0.692 & 20.529 & 0.904 & 0.007 \\
\hline Mental and behavioral disorders (F00-F99) & 0.766 & 60.550 & 1.067 & 0.115 \\
\hline Nervous system diseases (G00-G99) & 0.841 & 10.667 & 71.061 & 0.145 \\
\hline Eye and appendage diseases ( $\mathrm{H} 00-\mathrm{H} 59)$ & 0.009 & 90.001 & 0.067 & $<0.001$ \\
\hline Ear and mastoid diseases $(\mathrm{H} 60-\mathrm{H} 95)$ & 0.199 & 90.088 & 0.452 & $<0.001$ \\
\hline Circulatory diseases (I00-199) & 0.573 & 30.473 & 30.695 & $<0.001$ \\
\hline Respiratory diseases (J00-J99) & 0.763 & 30.625 & 0.931 & 0.008 \\
\hline Digestive diseases (K00-K93) & 0.331 & 10.266 & 0.412 & $<0.001$ \\
\hline Skin and subcutaneous tissue diseases (L00-L99) & 0.493 & 30.321 & 0.758 & 0.001 \\
\hline Musculoskeletal system and connective tissue diseases (M00-M99) & 0.750 & 0.597 & 0.941 & 0.013 \\
\hline Genitourinary diseases (N00-N99) & 0.414 & 40.328 & 0.522 & $<0.001$ \\
\hline Pregnancy, childbirth, and puerperium (000-099) & 0.244 & 40.168 & 0.353 & $<0.001$ \\
\hline Diseases that originated in the perinatal period (P00-P96) & 2.595 & 51.753 & 3.843 & $<0.001$ \\
\hline Congenital malformations, deformation, and chromosomal abnormalities (Q00-Q99) & 0.263 & 30.160 & 0.434 & $<0.001$ \\
\hline $\begin{array}{l}\text { Abnormal symptoms, signs, clinical and laboratory results, and cannot be classified in other categories } \\
\text { (R00-R99) }\end{array}$ & 0.222 & 20.120 & 0.413 & $<0.001$ \\
\hline Injury, poisoning and other external pathogenic factors (S00-T98) & 0.432 & 20.338 & 0.553 & $<0.001$ \\
\hline External causes of illness and death (V01-V98) & 0.476 & 60.378 & 30.598 & $<0.001$ \\
\hline
\end{tabular}

\section{Figures}




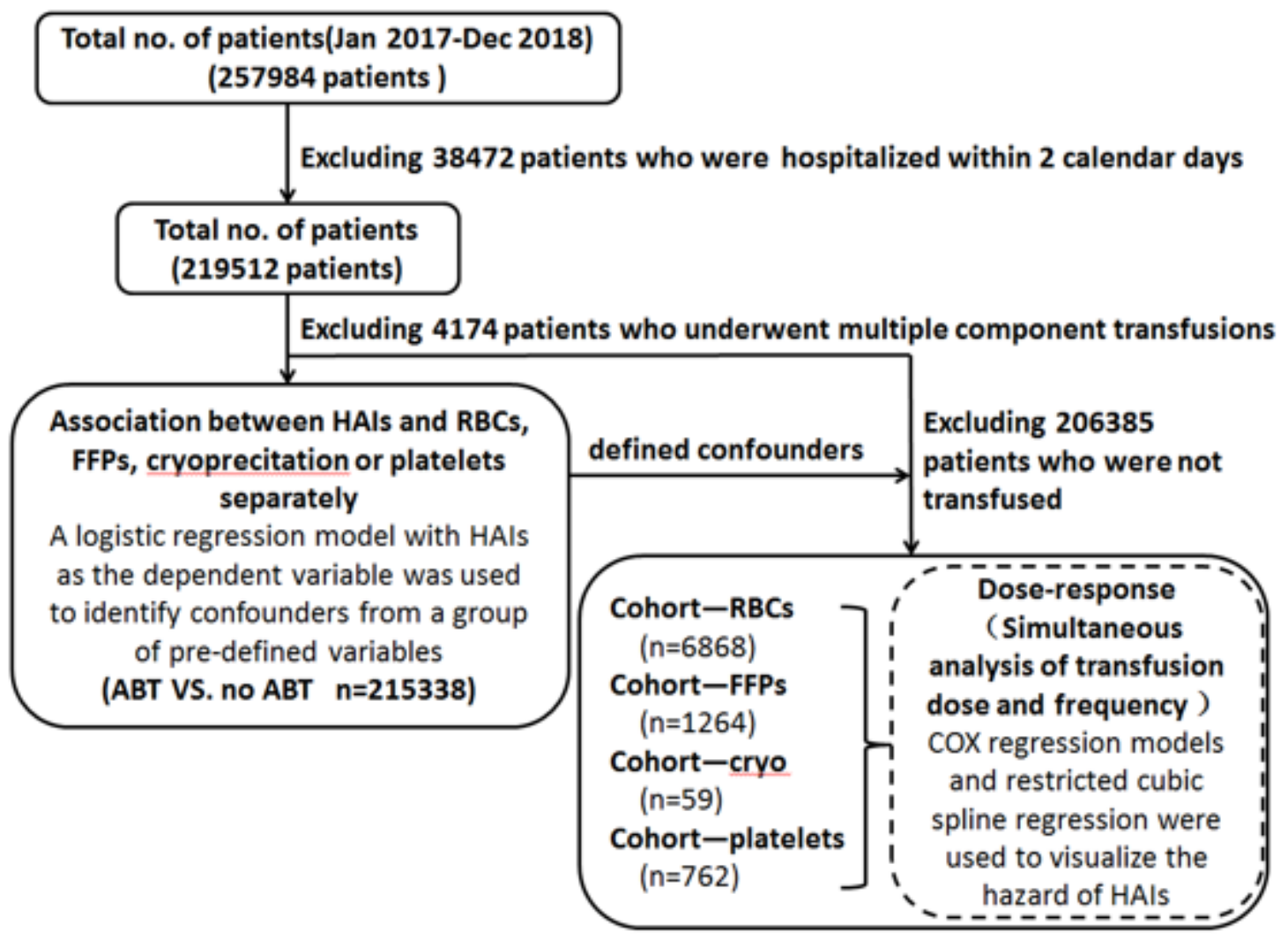

Figure 1

Flow chart of patient inclusion. A total of 257984 inpatients were admitted to the hospital. After data collation and screening, finally 3079 inpatients with HAI and 212259 inpatients without HAI were included. This study included 4 cohorts, including cohort-RBCs, cohort-FFPs, cohort-cryo and cohortplatelets. 
A.
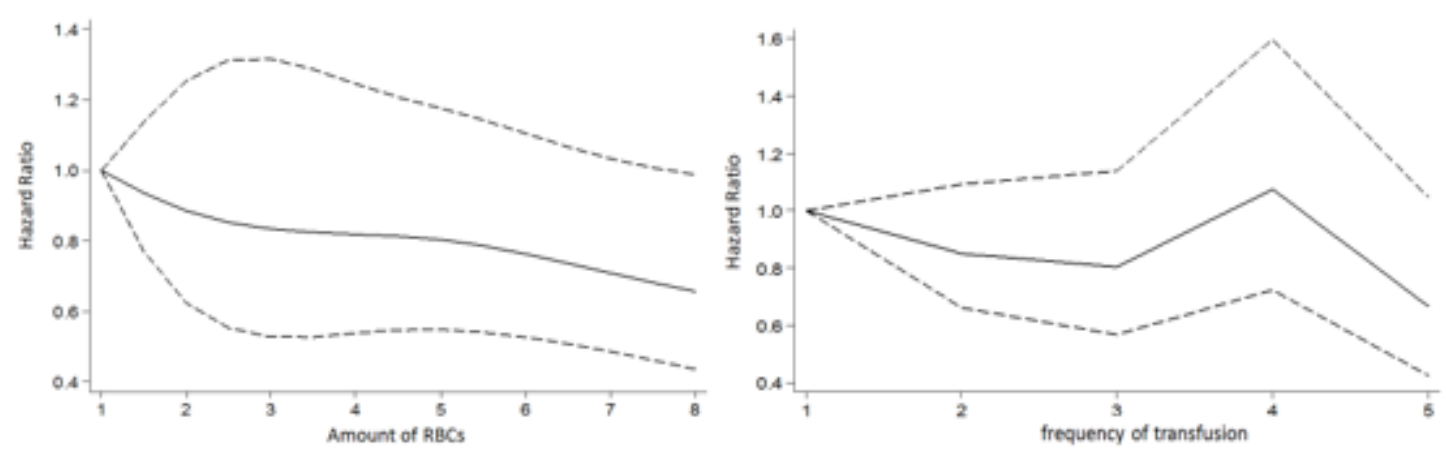

B.
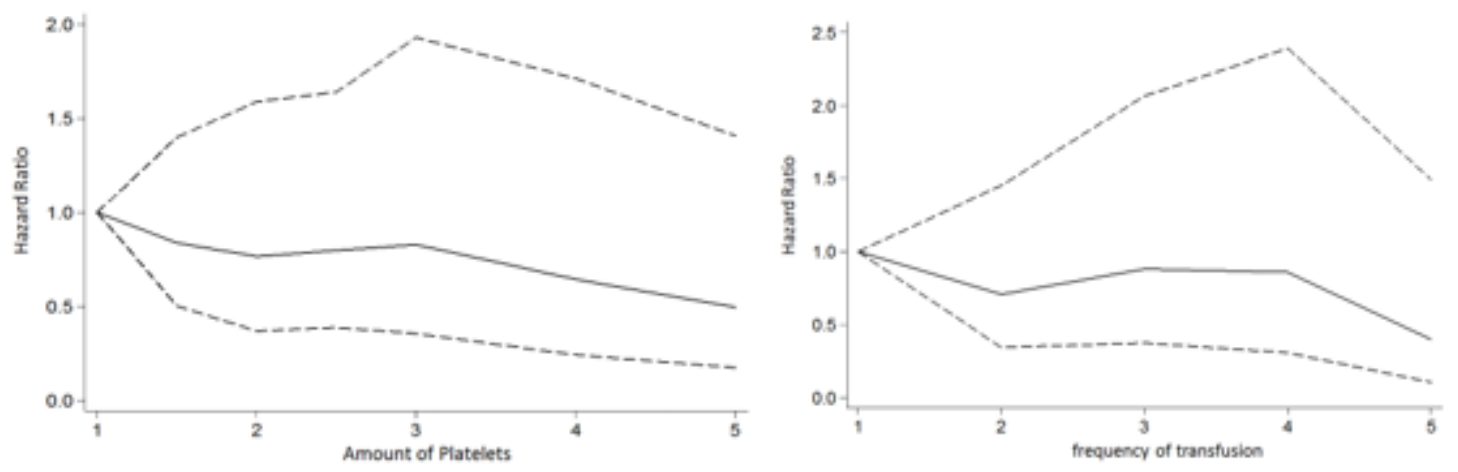

C.
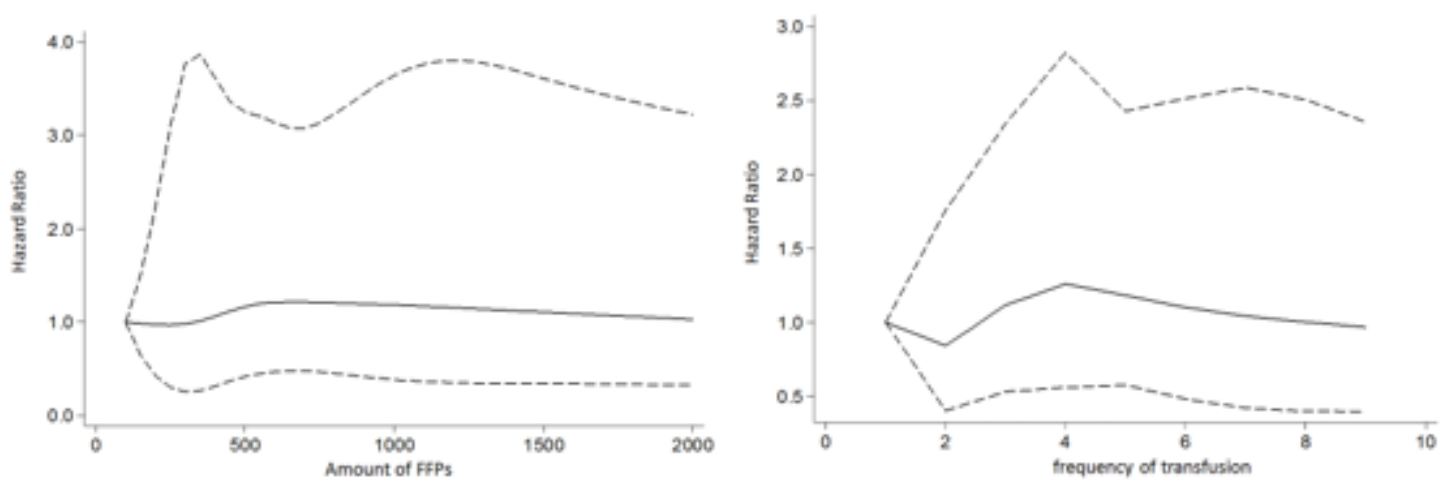

Figure 2

Dose-response relationship between transfusion products and HAI. A. There was no statistically significant change in the hazard ratio of HAI with the increase in the amount or frequency of RBCs transfusion. B. There was no statistically significant change in the hazard ratio of HAI with the increase in the amount or frequency of platelets transfusion. C. There was no statistically significant change in the hazard ratio of HAl with the increase in the amount or frequency of FFPs transfusion. 